\title{
LASER ULTRASONIC DETECTION OF THE SOLIDIFICATION FRONT
}

\section{DURING CASTING}

\author{
J. B. Walter and K. L. Telschow \\ Materials Physics Department \\ Idaho National Engineering Laboratory \\ Idaho Falls, ID 83415-2209
}

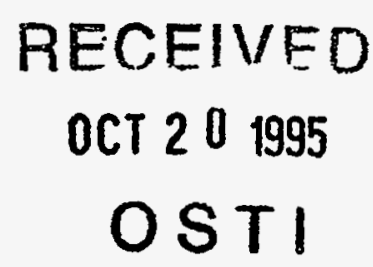

\section{INTRODUCTION}

A real-time sensor that directly measures properties of the solidification front would be a valuable aid to the metal casting industry. Information needed includes solidification front location, shape, and growth dynamics. The use of contacting probes is often undesirable because it can cause contamination and probe deterioration. Noncontacting laser ultrasonics offers an attractive solution to these problems, particularly if access to the free liquid surface is available. This paper presents results of laser ultrasonic measurements of the solidification front in tin and a tin-lead alloy. The ultrasonic waves were generated and detected at the liquid surface. Tin was selected for its low melting point and the availability of a suitable furnace. Results are presented for reflections from stationary and moving solidification fronts.

\section{STATIONARY SOLIDIFICATION FRONT MEASUREMENTS}

A vertical tube furnace was used to maintain the metal in both liquid and solid phases as shown in Figure 1. Both the pulsed laser generation beam and the detection beam were focussed on the liquid surface. A pulsed Nd-YAG laser, $10 \mathrm{~ns}, 4 \mathrm{~mm}$ spot size, $200 \mathrm{~mJ}$ pulse, generated uitrasonic waves in the liquid by ablation. Detection was accomplished with a confocal Fabry-Perot interferometer using an argon laser, focused a few millimeters from the generation spot, that provided a response approximately proportional to the velocity of the liquid surface $[1,2]$.

The ultrasonic wave, generated at the surface, traveled down to the solidification front, reflected, and was detected at the liquid surface a small distance away from the source beam. Simultaneously, a piezoelectric transducer generated ultrasonic waves at the bottom of the furnace that traveled up through the impedance matching block and into the solid tin. These waves reflected from the solidification front and also from the liquid surface and were detected by the same piezoelectric transducer. Utilization of both the noncontacting laser and the contacting piezoelectric methods provided a cross check on the depth of the front and a comparison between methods. 


\section{DISCLAIMER}

Portions of this document may be illegible in electronic image products. Images are produced from the best available original document. 


\section{DISCLAIMER}

This report was prepared as an account of work sponsored by an agency of the United States Government. Neither the United States Government nor any agency thereof, nor any of their employees, make any warranty, express or implied, or assumes any legal liability or responsibility for the accuracy, completeness, or usefulness of any information, apparatus, product, or process disclosed, or represents that its use would not infringe privately owned rights. Reference herein to any specific commercial product, process, or service by trade name, trademark, manufacturer, or otherwise does not necessarily constitute or imply its endorsement, recommendation, or favoring by the United States Government or any agency thereof. The views and opinions of authors expressed herein do not necessarily state or reflect those of the United States Government or

any agency thereof. 


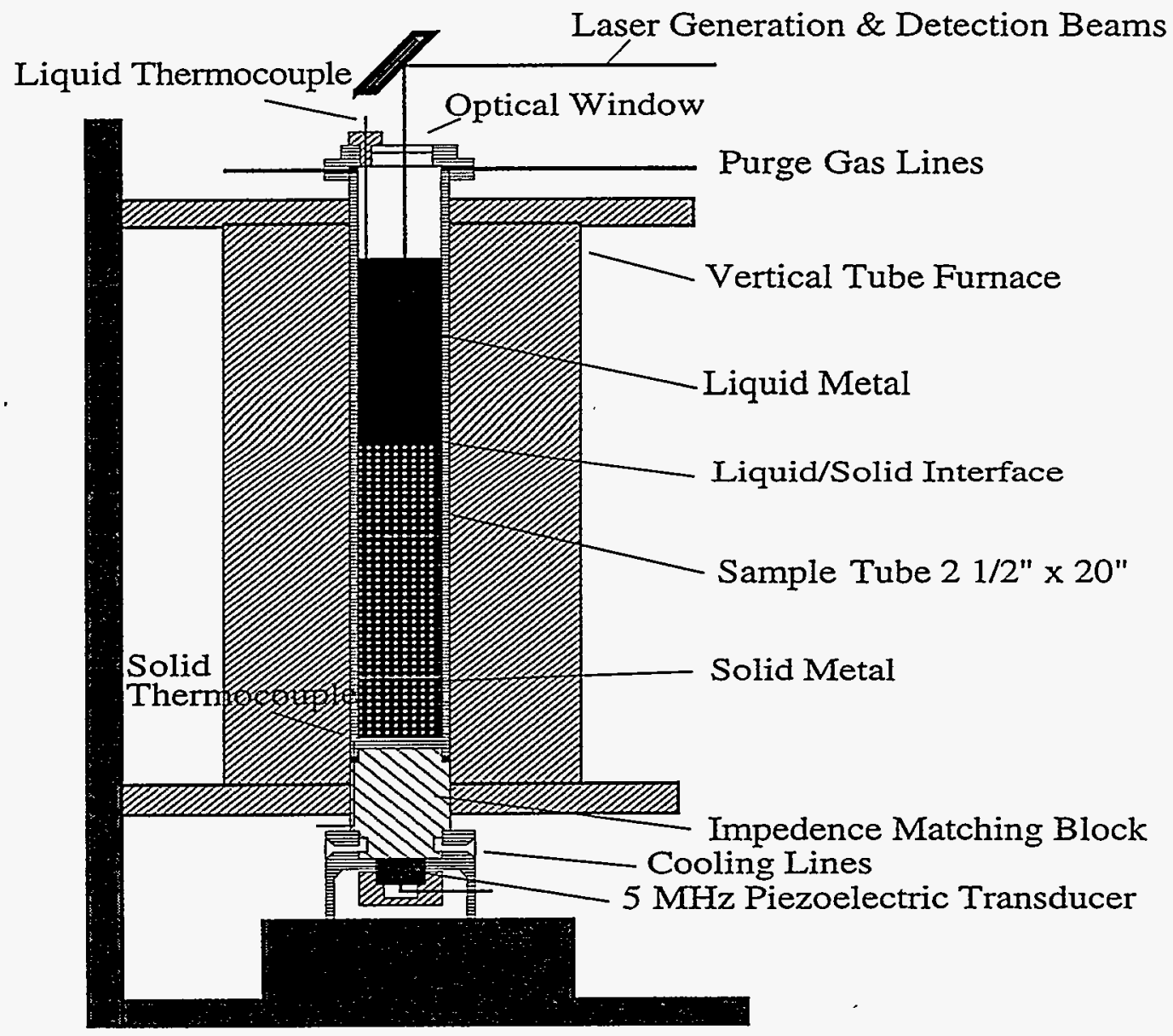

Figure 1. Molten metal casting furnace for laser/piezoelectric experiments.

Waveforms showing the solidification front echo are displayed in Figure 2. The upper trace shows the laser-generated echo with a travel time of about $37 \mu \mathrm{s}$. The lower trace shows the piezoelectric-generated echo recorded at $195 \mu$ and the echo from the liquid surface at about $232 \mu \mathrm{s}$. The time for the wave to travel from the solidification front to the surface and back is again seen to be about $37 \mu \mathrm{s}$. Figure 2 shows that both measurement techniques locate the interface about $45 \mathrm{~mm}$ below the liquid surface. Differences between the two ultrasonic techniques are also seen in Figure 2. The laser method is wideband, producing a narrow echo signal pulse, whereas the piezoelectric method is essentially narrowband, producing a signal characteristic of transducer ringing. The laser results are also free of spurious signals from internal reflections in the impedance matching block such as are present in the piezoelectric recorded waveforms, that often complicate signal source identification.

The location of the solidification front was altered by changing the temperature gradient along the tin column. Figures 3 and 4 show the progression of the solidification front at various stationary depths for the laser and piezoelectric techniques respectively. The sharp signature of the solidification front in Figure 3 moves to longer times, from 31 to $88 \mu$ s, reflecting the longer path for the laser-generated ultrasonic pulse through the molten metal. The solidification front echo in Figure 4 moves to shorter times, from 211 to $160 \mu \mathrm{s}$, reflecting the shorter path for the piezoelectric generated pulse through the solid tin. The liquid surface echo in Figure 4 moves to longer times, from 230 to $250 \mu$ s, because the sound speed is slower in the liquid. The stationary signals in Figure 4 are associated with various echoes in the impedance matching block. Figure 3 also shows a strong, but slowly varying, additional waveform in the laser ultrasonic measurement. This is due to the acoustic wave generated by the 

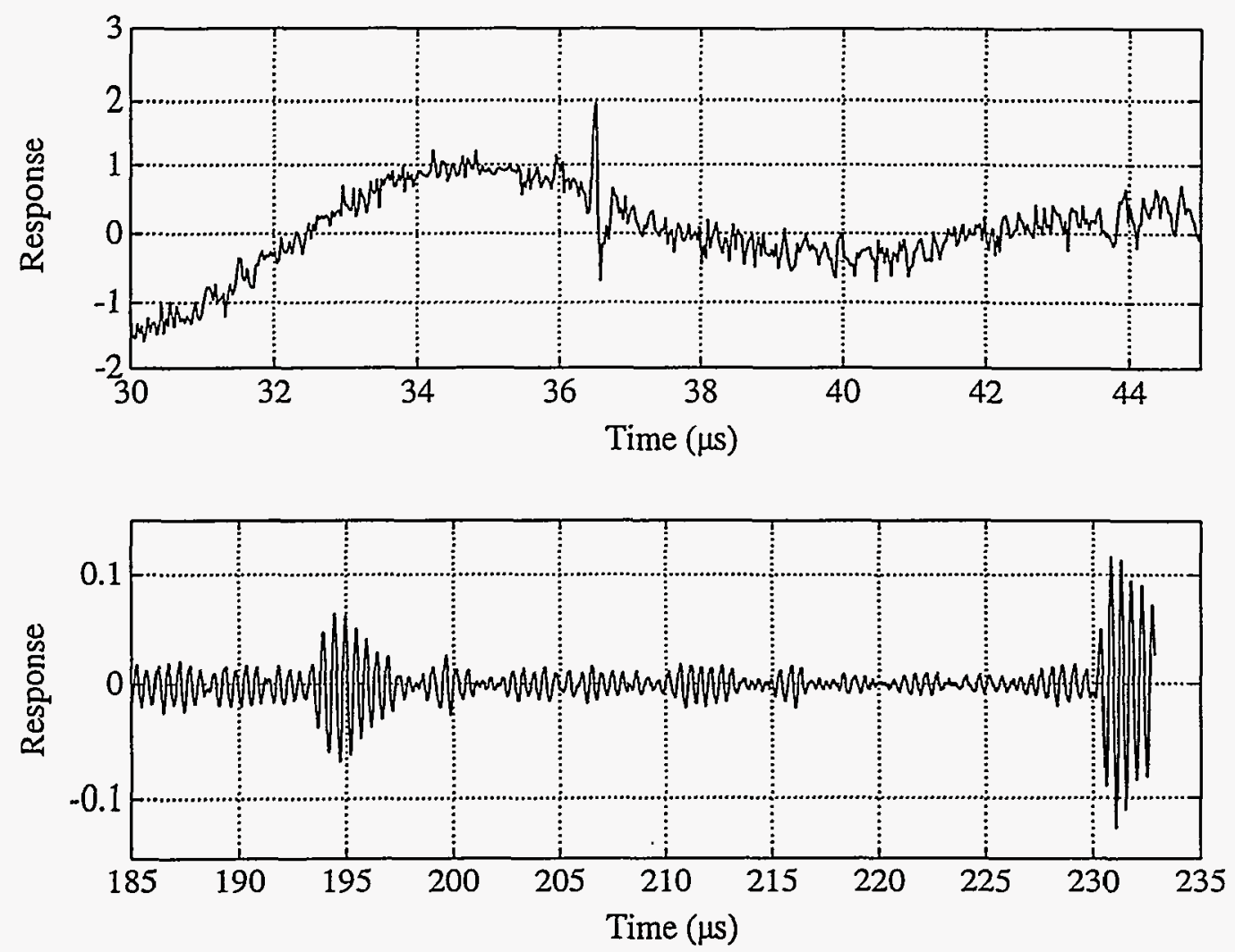

Figure 2. Solidification front reflection echoes recorded at the surface of the liquid with the laser technique (upper, at $37 \mu$ s) and at the bottom of the solid with the contact piezoelectric technique (lower, at $195 \mu \mathrm{s}$ ).

ablation pulse. Liquid surface vibrations also degrade the laser detection process. All laser ultrasonic waveforms presented in this paper are single shot. Surface contamination effects on the molten metal also were a factor in determining the generation efficiency for the laser source; however, repetition of the high energy laser pulse was found to clean the surface. Some differences in solidification front echo signal amplitude were caused by conditions of the solidification front. As the heat flow was altered, a flat solidification front surface was not always found, resulting in decreased reflection signal amplitude. The front could be made more planar, increasing the reflection signal amplitude, by holding the temperature gradients constant in order to achieve a local equilibrium. The reflection signal amplitude is an indication of the solidification front profile and structure.

\section{MOVING SOLIDIFICATION FRONT}

Measurements with a moving solidification front were made with the furnace insert depicted in Figure 5. The tin column is considerably shorter than that shown in Figure 1 and the piezoelectric transducer was eliminated. This improved control of the heat flow. As in the initial setup, the generation and detection laser beams were incident on the liquid surface.

The first measurement with this setup was of a moving front in about $80 \mathrm{~mm}$ of pure tin. Laser ultrasonic signals, with the tin solidifying at about $1 \mathrm{~mm} / \mathrm{min}$, are displayed in Figure 6. Besides the usual "air wave" signals, the solidification front echo can be seen moving from about 52 to $26 \mu \mathrm{s}$, indicating the pool depth has shrunk from 64 to $32 \mathrm{~mm}$. Figure 6 shows the echo signal amplitude greatly decreased for a solidification front evolving in time as compared to those described earlier for a stationary front. 


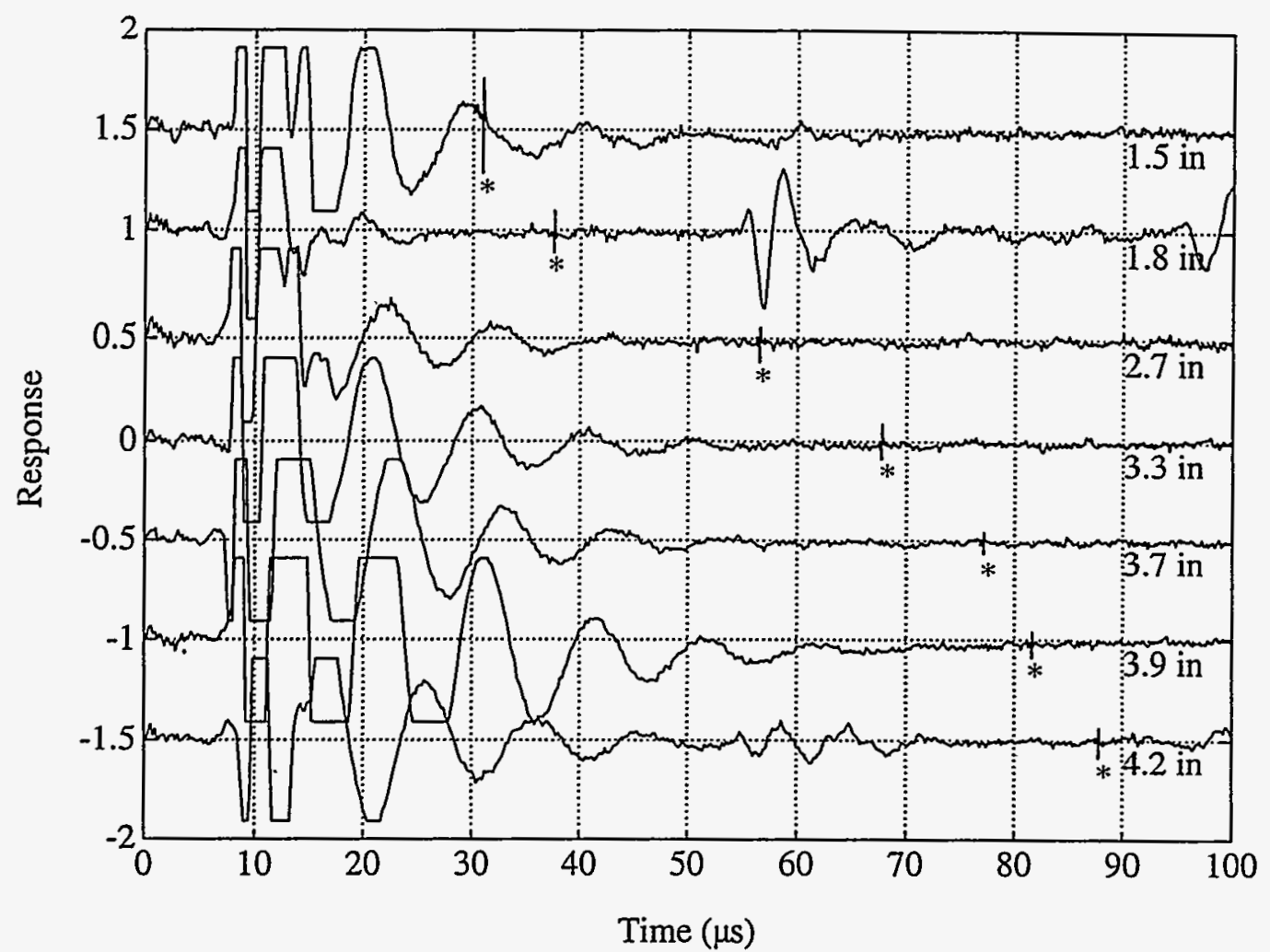

Figure 3. The solidification front in tin measured by the laser ultrasonic method $\left(^{*}\right)$. The large slow oscillations result from acoustic waves in gas above the liquid.

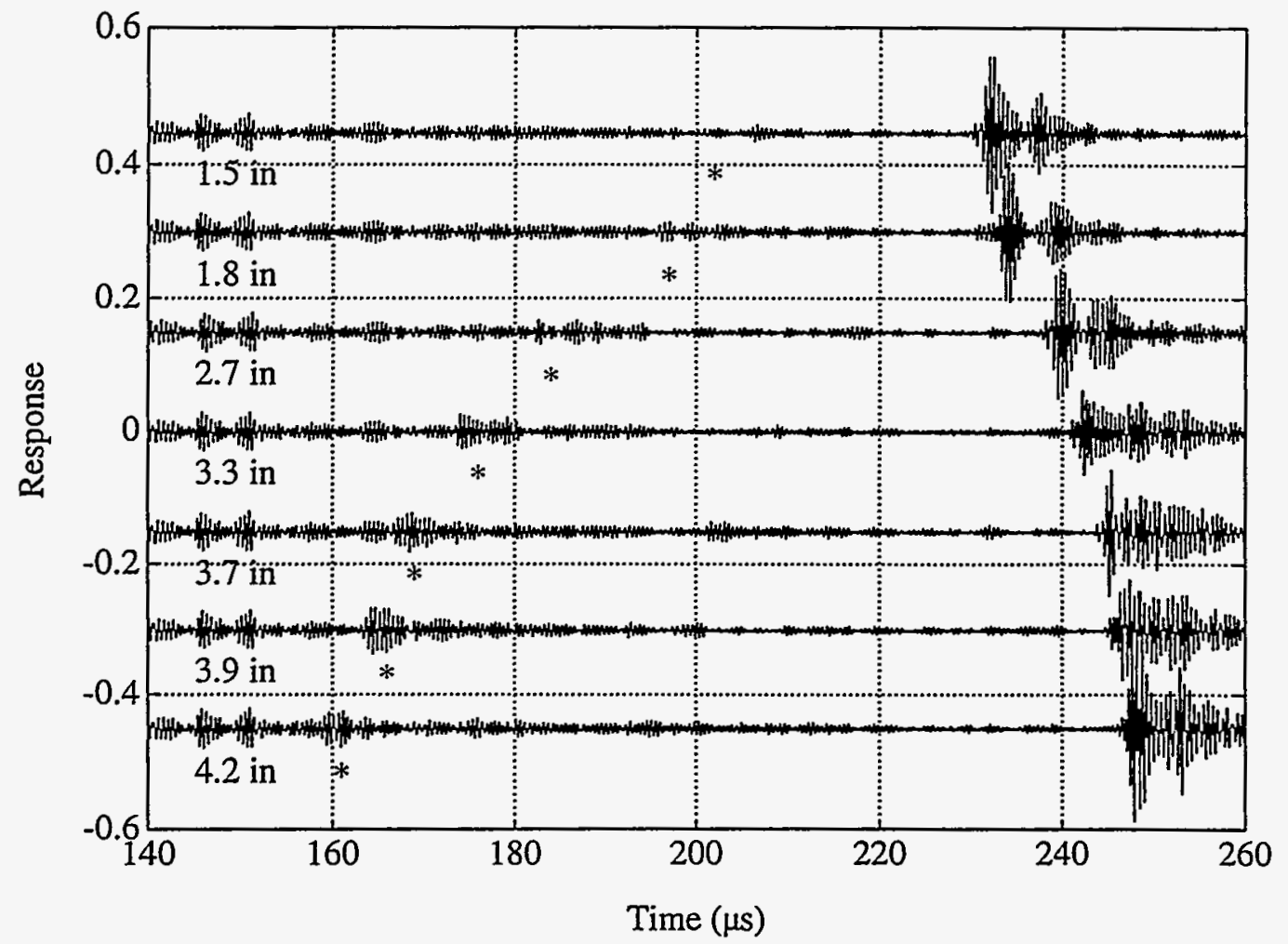

Figure 4. Piezoelectric measurement of the solidification front location in tin $\left(^{*}\right.$ marks time determined from the laser data). The stationary signals are from the impedance matching block. The strong reflections past $220 \mu \mathrm{s}$ are from the liquid surface.

\section{ALLOY MEASUREMENTS}

A set of thermocouples was inserted at fixed depths into the metal to measure the temperature as a function of depth. This permitted an estimation of the depths at which 
Stainless Steel Container

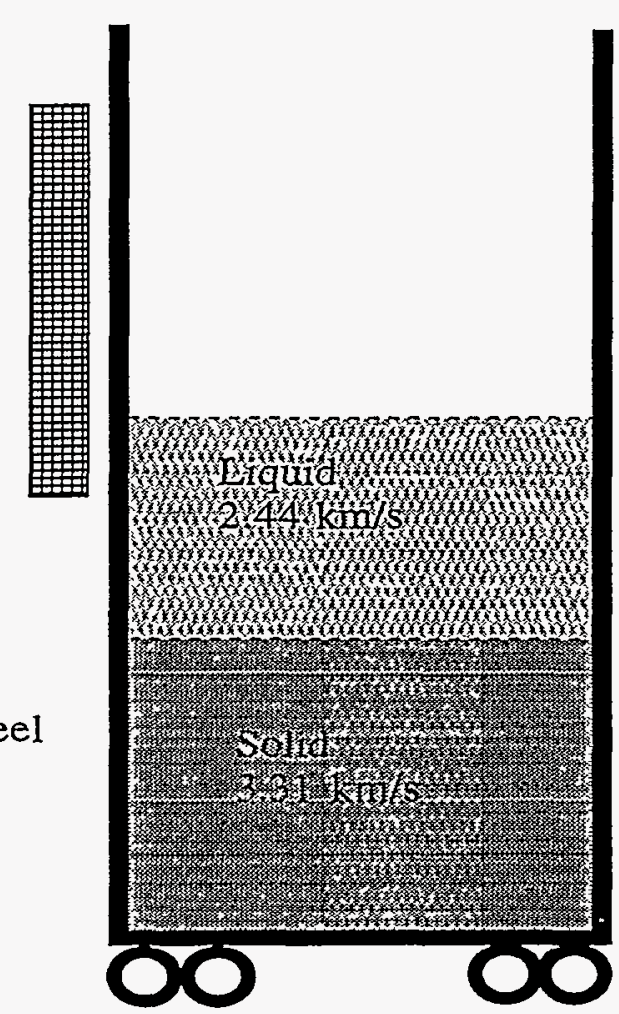

Heating Element

Figure 5. Furnace insert for moving solidification front experiments.

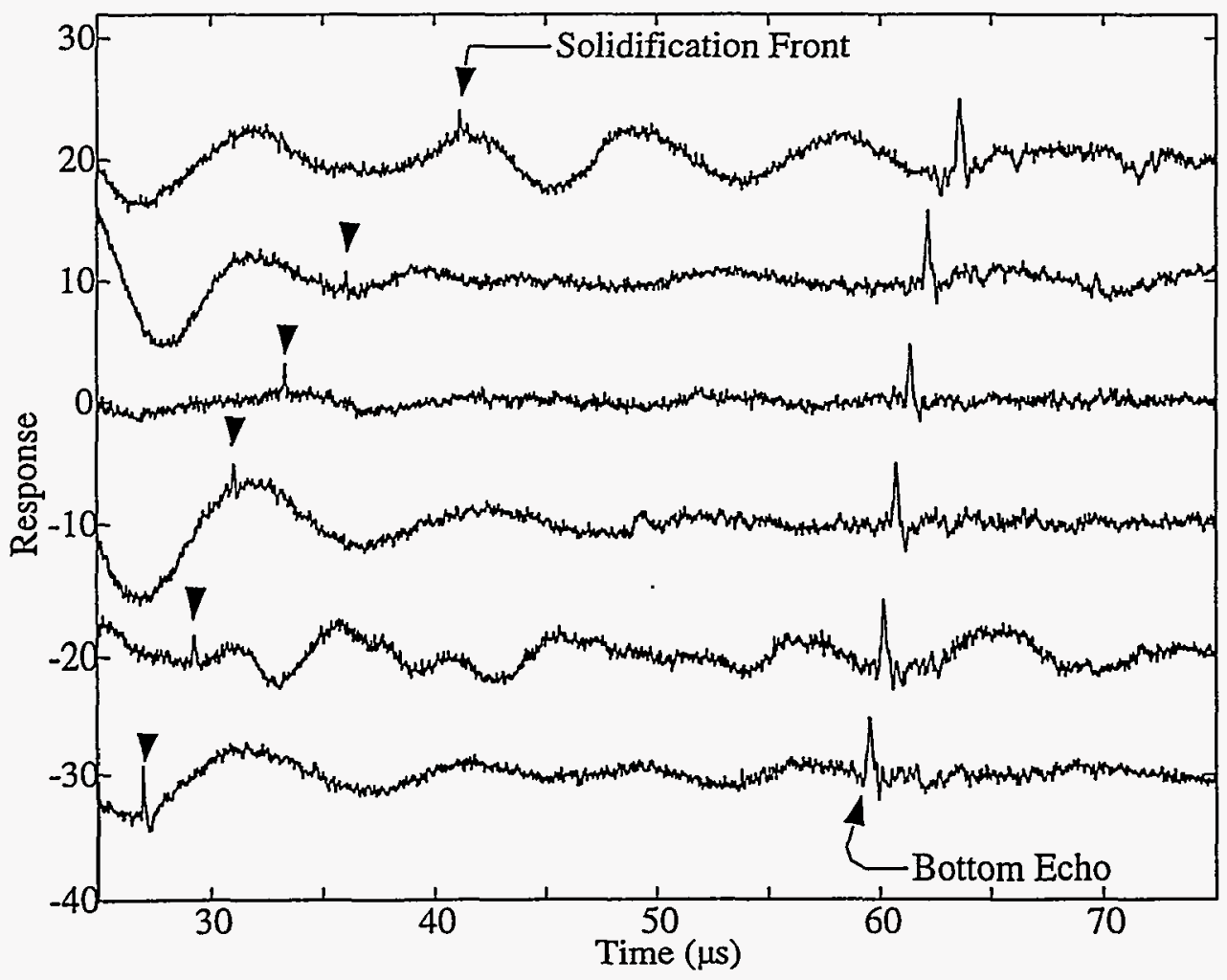

Figure 6. Laser signals for a moving solidification front $(1 \mathrm{~mm} / \mathrm{min})$ in tin. All waveforms are single shot. The data span 30 minutes.

the liquidus and solidus temperatures from the tin-lead phase diagram were reached the difference approximates the mushy zone thickness [3]. Lead was selected to form an alloy with tin because only a small addition, $0.6 \%$, was needed to produce a significant mushy zone (solidus and liquidus at about 220 and $231^{\circ} \mathrm{C}$, respectively). The ultrasonic generation, detection, and propagation properties of the liquid and solid were still essentially the same as those for pure tin. Experiments with the $0.6 \% \mathrm{~Pb}$ alloy 
were more difficult, as expected. Geometry, particularly of the generation and detection spots relative to the solidification front, was important, consistent with earlier work on laser generation in molten metal [4]. Both the solidification front and the bottom echoes were difficult to detect except when the solidification front moved at less than about $0.1 \mathrm{~mm} / \mathrm{min}$. Figure 7 shows data for the alloy. The mushy zone is about $8 \mathrm{~mm}$ thick, and is nearly stationary with the alloy solidifying at $0.1 \mathrm{~mm} / \mathrm{min}$. The solidification front echo appears in six of the traces at about $50 \mu$ s. The bottom echoes extend from about 67 to $73 \mu$ s, indicating a large amount of internal scattering taking place as the wave travels through the mushy zone.

Figure 8 shows the solidification front signal acquired for an $8 \mathrm{~mm}$ and a $12 \mathrm{~mm}$ mushy zone, in both cases solidifying at about $0.05 \mathrm{~mm} / \mathrm{min}$. The moving solidification front signal for pure tin from Figure 6 is shown for comparison. The signals are similar, with little additional scattering due to the mushy zone. This suggests that the recorded echo signal comes from scattering by localized predominant features rather than from throughout the mushy zone.

\section{CONCLUSIONS}

The location of the solidification front in pure tin and also in a $0.6 \% \mathrm{~Pb}$ alloy with a mushy zone was successfully recorded using laser ultrasonic methods. Reflections from the stationary solidification fronts were considerably larger than those from moving fronts. The presence of a mushy zone in the alloy decreased the reflection signal amplitude. Averaging and other signal processing techniques could be used to significantly enhance the solidification front reflection signal. Laser ultrasonic methods show potential for studying the properties of solidification in metals through the reflected signal amplitude. Solidification front shape, growth structure, and growth rate all affect the signals measured.

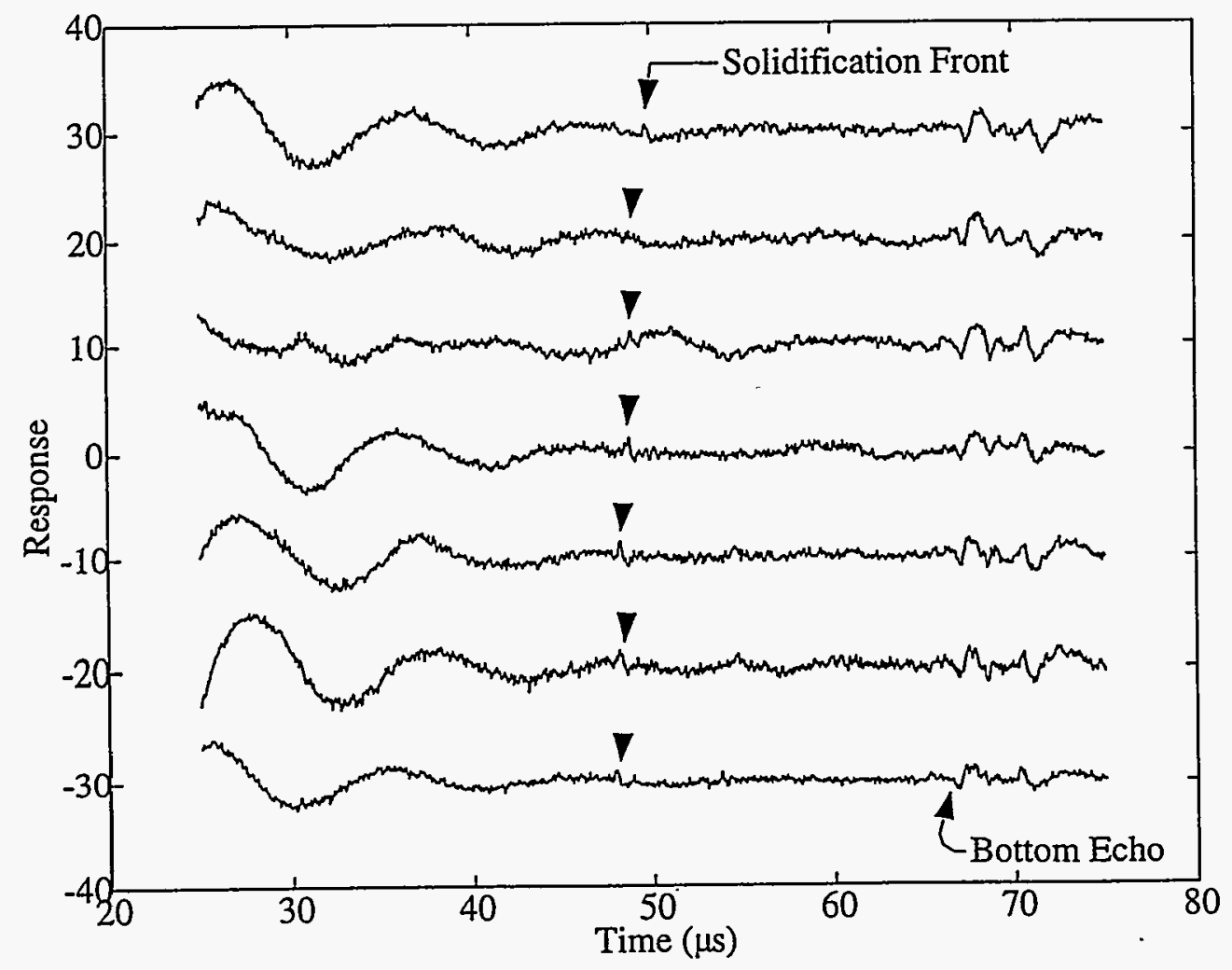

Figure 7. Laser signals from a moving solidification front $(\sim 0.1 \mathrm{~mm} / \mathrm{min})$ in a tin-lead $(0.6 \%)$ alloy. All waveforms are single shot and span about 30 minutes. 


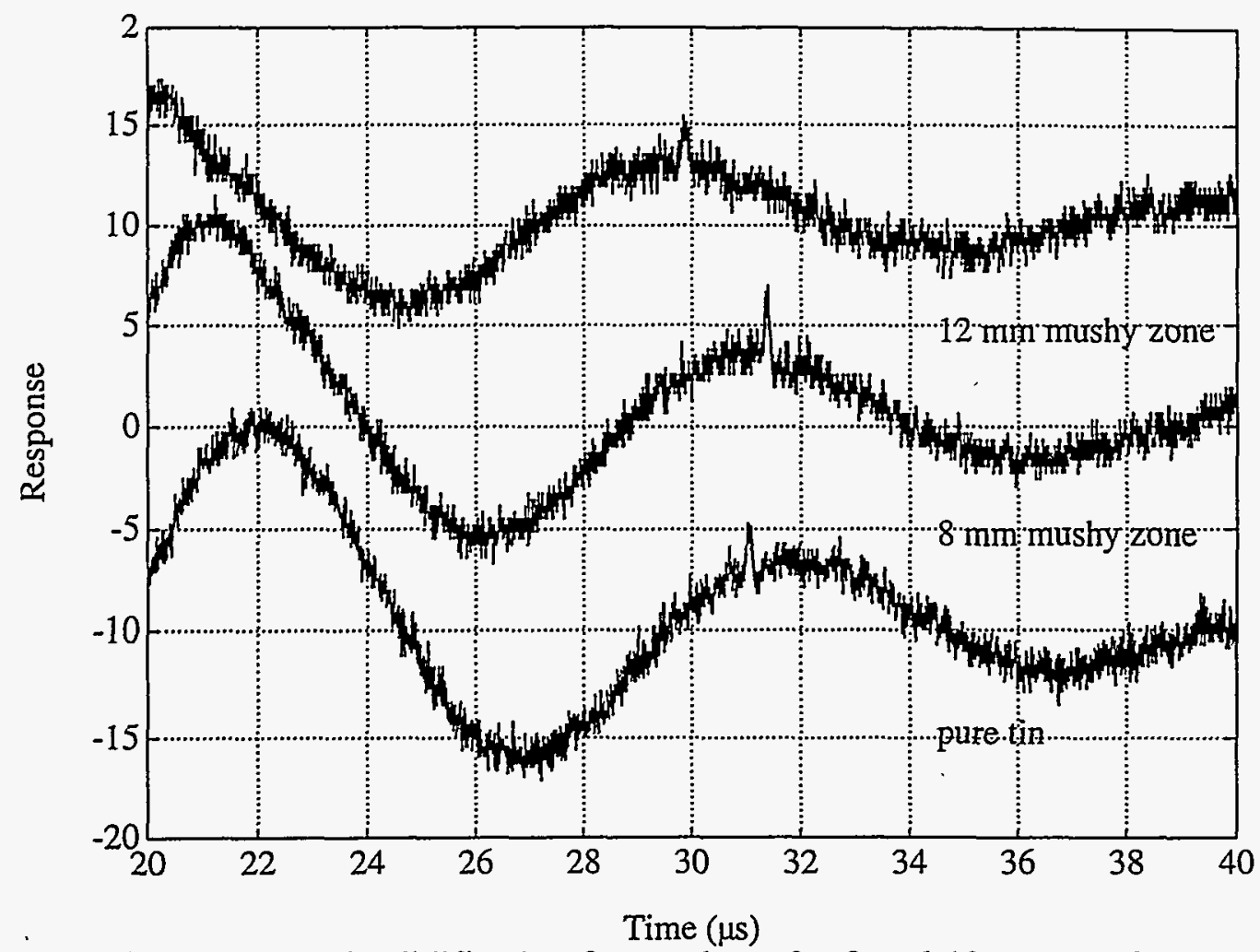

Figure 8. Comparison of solidification front echoes for 8 and $12 \mathrm{~mm}$ mushy zones with that of a moving front in pure tin (Figure 6).

\section{ACKNOWLEDGMENTS}

The work described in this paper was supported by the Interior Department's Bureau of Mines under Contract No. J0134035 through DOE Idaho Operations Office Contract DE-AC07-94ID13223.

\section{REFERENCES}

1. J.-P. Monchalin and R. Héon, "Laser Ultrasonic Generation and Detection with a Confocal Fabry-Perot Interferometer," Materials Evaluation, 44, 1231 (1986).

2. K. L. Telschow, J. B. Walter, G. V. Garcia, "Laser Ultrasonic Monitoring of Ceramic Sintering," J. Appl. Phys. $\underline{68}$ (12), 1990, 6077-6082.

3. Private communication from W. J. Boettinger and R. J. Schaefer of the Metallurgy division, National Institute of Standards and Technology, Gaithersburg, May 1995.

4. J. B. Walter, K. L. Telschow, and R. J. Conant, "Laser Ultrasonic Generation at the Surface of a Liquid Metal", Review of Progress in QNDE, Vol. 14, edited by D. O. Thompson and D. E. Chimenti (Plenum Press, New York, 1995) 507-512.

\section{DISCLAIMER}

This report was prepared as an account of work sponsored by an agency of the United States Government. Neither the United States Government nor any agency thereof, nor any of their employees, makes any warranty, express or implied, or assumes any legal liability or responsibility for the accuracy, completeness, or usefulness of any information, apparatus, product, or process disclosed, or represents that its use would not infringe privately owned rights. Reference herein to any specific commercial product, process, or service by trade name, trademark, manufacturer, or otherwise does not necessarily constitute or imply its endorsement, recommendation, or favoring by the United States Government or any agency thereof. The views and opinions of authors expressed herein do not necessarily state or reflect those of the United States Government or any agency thereof. 